\title{
The pathology of command and control: a formal synthesis
}

\author{
Michael Cox ${ }^{1}$
}

\begin{abstract}
One of the most important theories in the study of environmental governance and policy is the pathology of command and control, which describes the negative consequences of top-down, technocratic governance of social and ecological systems. However, to date, this theory has been expressed somewhat inconsistently and informally in the literature, even by the seminal works that have established its importance and popularized it. This presents a problem for the sustainability science community if it cannot be sure of the precise details of one of its most important theories. Without such precision, applications and tests of various elements of the theory cannot be conducted reliably to advance the knowledge of environmental governance. I address this problem by synthesizing several seminal works to formalize this theory. The formalization involves the identification of the individual elements of the theory and a diagrammatic description of their relationships with each other that unfold in a series of semi-independent causal paths. Ideally, with such a formalization, scholars can use this theory more reliably and more meaningfully in their future work. I conclude by discussing the implications this theory has for the governance of natural resources.
\end{abstract}

Key Words: centralization; command and control; theoretical synthesis

\section{INTRODUCTION}

Many scholars have criticized the governance and management of social and ecological systems by centralized bureaucratic agencies. Of these, several works stand out for their comprehensiveness and the academic impact of their arguments (Holling and Meffe 1996, Scott 1998, Acheson 2006). Moreover, although there is a large amount of literature that is broadly relevant to this topic, each of these three works is distinctive in the extent to which it isolates distinct elements and processes that constitute this governance and management dynamic, and each provides illustrative examples of these processes.

There are common elements across each of these three works, namely the presence of a centralized, technocratic governance system that imposes "technical fixes" on a target system by applying a large amount of control. Holling and Meffe (1996) describe what they call "the pathology of natural resource management," which results from a "command and control" style of natural resource management. Acheson (2006) describes the failure of several different broad types of natural resource management, including the approach of top-down, "scientific" management.

Scott's (1998) approach is distinct in that he focuses not only on natural resource management but also on the governance of social systems. He describes several elements common to centralized governance that he argues lead to predictably negative results. $\mathrm{He}$ labels these as follows: an "authoritarian ordering of nature and society," "high modernist ideology," an "authoritarian state," and a "prostrate civil society." Scott's (1998:5) central argument reads, "In sum, the legibility of a society provides the capacity for largescale social engineering, high-modernist ideology provides the desire, the authoritarian state provides the determination to act on that desire, and an incapacitated civil society provides the leveled social terrain on which to build."

The theory of the pathology of command and control (TPCC) is an important theory in the field of environmental governance. However, to date, this theory has been expressed somewhat inconsistently and informally in the literature, even by these seminal works. The arguments are expressed solely in natural language, which allows for multiple interpretations of the key concepts and their relationships.

This presents a problem for the research communities that engage with this theory if they cannot be reliably sure of its details. Without such precision and consistency, applications and tests of various elements of the theory cannot be conducted reliably to advance the knowledge of environmental governance. More generally, communication among scientists can be severely hampered if each can be using the same term to mean something quite different, without anyone necessarily knowing that this is the case.

A very popular and important theory that has been the subject of just this kind of confusion is the tragedy of the commons, as popularized by Hardin (1968). There has been much debate and confusion regarding the precise meaning of this theory, with some interpreting it to mean that common-property arrangements are inherently inadequate, and others maintaining that its prediction of commons decline is in fact predicated on the absence of any type of property arrangement, such that that the theory is really describing the tragedy of open-access commons (Ostrom et al. 1999). Ostrom et al. (1999:278) describe the problems that have arisen from this confusion:

\section{The starkness of Hardin's original statement has been used by many scholars and policy-makers to rationalize central government control of all common-pool resources and to paint a disempowering, pessimistic vision of the human prospect. Users are pictured as trapped in a situation they cannot change. Thus, it is argued that solutions must be imposed on users by external authorities}

While it is important to allow for multiple interpretations of a particular scientific concept or theory, this comment reflects how this allowance can become problematic when distinct assumptions and interpretations are not made explicit. Moreover, such problems can result even when the tragedy of the commons 
Fig. 1. Formalization of the theory of the pathology of command and control.

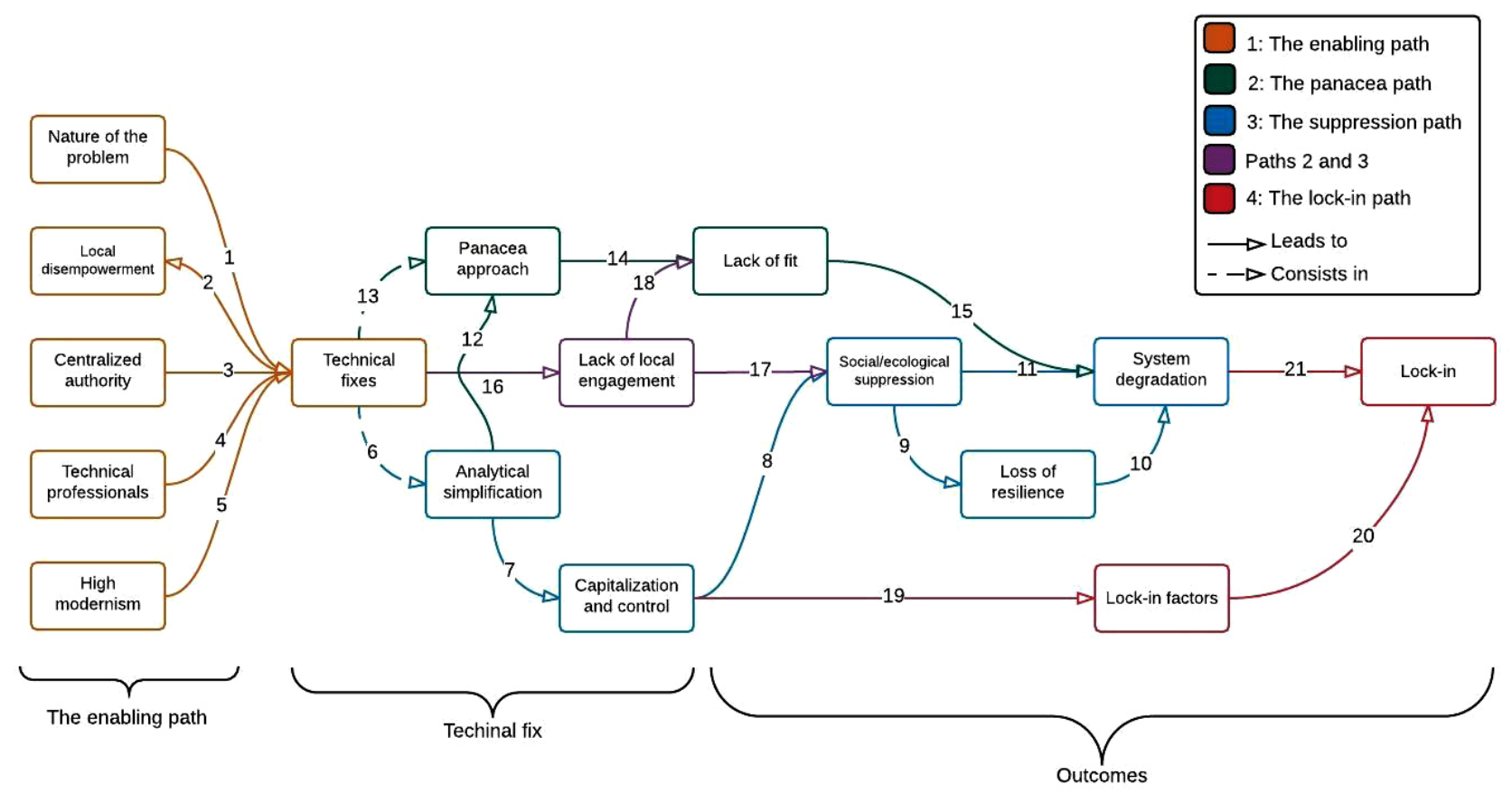

theory is not actively being tested by commons scholars but is being used more as an initial context to motivate a particular analysis or intervention.

In Ostrom's (2007) paper advocating for conceptual clarity and consistency in the analysis of complex social-ecological systems, she attempts to describe, in a more precise way, what this theory actually involves. In doing so, she clarifies just what are the preconditions stipulated by Hardin (1968) for commons degradation by a set of resource users. Here, I attempt to accomplish a similar task for TPCC by clarifying and synthesizing the arguments made by the three authors introduced above. In so doing, I also attempt to strengthen the connection between the various literature bases that the seminal works represent. I conclude by discussing some implications this theory has for the practice and science of environmental governance.

\section{THE PATHOLOGY OF COMMAND AND CONTROL}

\section{Conceptual clarifications}

Before describing TPCC, I first clarify what I mean by the term "theory" as well as the term "command and control." Theory, as a term, does not have a consistent definition across, or even sometimes within, disciplines. My own understanding is based on Schlager (2007:296), who states that theories "place values on some of the variables identified as important in a framework, posit relationships among the variables, and make predictions about likely outcomes."

Building on this definition, Cox et al. (2016a:47) define a scientific theory as "a statement that describes (1) a relationship between an outcome and a set of independent variables, the values of which are argued to be sufficient for predicting the outcome, and (2) a mechanism by which this relationship occurs." As Cox et al. (2016a) discuss, many of the variables that are implicitly or explicitly employed in social-ecological theories are binary, indicating simply the presence or absence of a particular element of a phenomenon. In this case, a theory would describe (and explain) the subsequent appearance of additional elements based on the occurrence of an initial set, ultimately leading to one or more outcomes of interest. Each element identified by a theory then becomes an independent observational prediction and a means to test the theory. Recognizing that there are other valid uses of the term, this is my understanding of the term "theory" when I describe TPCC as such.

Next, I am using the term "command and control" the way Holling and Meffe (1996) use it: to indicate a problematically large degree of authoritative centralization and control in a governance system, rather than a particular type of policy instrument (e.g., regulations instead of incentive-based instruments), as it is more commonly used. I believe this is in fact a more appropriate use of the term for two reasons. First, the term "command and control" is generally pejorative and so should probably be used to refer to a pathology rather than to a set of policy instruments. It is perhaps unsurprising that the literature that uses "command and control" to refer to regulations tends to favor other policy options (e.g., incentive-based or market-based instruments; Stavins 2003). Even the use of the term introduced by Holling and Meffe (1996) should not be taken as a universal condemnation of all of the elements they and other authors associated with it because several 
aspects of the pathology are somewhat unavoidable, if not in fact desirable, under some circumstances, as I will discuss in more depth.

Second, an authoritative governing organization directing activities and behaviors from the top down seems more accurately to embody the term "command and control" than does, say, a technological mandate, which, after all, is a common type of regulation used by comparatively decentralized resource-user communities in managing their own resources (Acheson and Wilson 1996).

\section{Main elements of the theory}

When combined, the arguments from Holling and Meffe (1996), Scott (1998), and Acheson (2006) produce a theoretical statement (Fig. 1). This argument is constituted by a set of elements that either cause each other to occur or contain each other, in which case, one element helps constitute another. These connections are denoted by numbered arrows (Fig. 1), which I will refer to in brackets (e.g., [1]).

The elements of TPCC are grouped in two ways (Fig. 1). First, there are several different sets of arguments or paths contained within TPCC. The first path $[1,2,3,4,5]$ describes the context that facilitates the development and implementation of a technical fix. The second path, panacea $[12,13,14,15,16,18]$, describes how such technical fixes often fit poorly with local context and thus lead to commons degradation. The third path, suppression $[6,7,8,9,10,11,16,17]$, describes how technical fixes suppress local variation and function. The final path, lock-in [19, $20,21]$, describes how systems struggle to extricate themselves from the pathology.

Second, the elements can also be grouped into three sequential categories along which the paths proceed: (1) the enabling environment, (2) the technical fix, and (3) outcomes (Fig. 1). I next provide a brief description of each element, grouped by these categories. After each element, I label whether the argument is described in each of the three main works (HM = Holling and Meffe 1996, JS = James Scott 1998, JA = James Acheson 2006).

1. The enabling path: the problematic development of technical fixes is associated with the following elements:

- The nature of the problem or system: As Holling and Meffe (1996:329) describe, much of the problem of applying command-and-control strategies is a result of their application to a "complex, nonlinear, and poorly understood" system (HM);

- Local disempowerment: This reflects what Scott (1998) refers to as a "prostrate civil society," or the disempowerment of local citizens and resource users, which is in turn exacerbated by the implementation of the technical fix from the top down (JA, JS);

- Centralized authority: The presence of a centralized, bureaucratic, decision-making apparatus that claims strong jurisdictional authority over a large target system and that has substantially more power than other actors in civil society (JA, JS);

- Technical professionals: A set of licensed managerial professionals who promote a technical fix as a particular way of resolving a perceived problem and who face professional incentives to offer particular prescriptions over others (JA, JS);

- High modernism, or the unskeptical belief on the part of decision makers in the ability of "comprehensive planning of human settlement and production to bring about social progress" (Scott 1998:4; JS).

2. Each technical fix is aimed at a particular type of problem as it arises in a target system and can involve technological and institutional components. Technical fixes involve the following elements:

- Panacea approach: Each is based on the presumption that this fix is a panacea or that it can be applied universally without regard to local context or variation (JA, JS);

- Analytical simplification: Each is based on the presumption that "the problem is well-bounded, clearly defined, relatively simple, and generally linear with respect to cause and effect" (Holling and Meffe 1996:329; HM, JS); Goal myopia: This simplification focuses primarily or exclusively on one or a few "productivist" outputs without much concern for the trade-offs this might involve. These aspects are then quantitatively measured to make the system technically "legible;"

- Analytical leverage: The simplification generally provides a method to intervene in the system so as to maximize this output; Capitalization and control: Implementing a technical fix requires the exertion of substantial amounts of control over the target system to impose the analytical simplifications onto the target system. This control is frequently exercised through the introduction of new physical capital and machinery. This process therefore frequently involves mechanization (HM, JS); L Lack of local engagement: Technical fixes are frequently implemented without extensive input from local communities of natural resource users or much understanding of their institutional traditions and, therefore, do little to incorporate their local social and ecological knowledge or practices (JA, JS).

3. Outcomes: Several sets of outcomes result from the implementation of technical fixes:

- Lack of fit: Rules and technologies that are applied to a target system without regard to local social or ecological conditions tend to fit poorly with these conditions (JA, JS);

- Suppression of local social and ecological function: In imposing its own artificially simplified model of the target system onto this system, the technical fix reifies this simplification. As a result, important social and ecological functions are disregarded and often actively suppressed. This reduces the functional complexity of the system to maximize its productivity or efficiency (HM, JA, JS);

- Loss of resilience: This reduction in variation and complexity undercuts the integrity of the target system and causes it to be increasingly vulnerable to disturbances (HM, JS);

- System degradation: As a result of decreased socialecological complexity and poor fit, over time, important 
social and ecological processes and functions that are left out of the "synoptic view" imposed by managers start to deteriorate. Because the target system depends on these processes, the larger system begins to deteriorate as well (HM, JA, JS);

- Lock-in factors: Several factors that are established by the enabling environment and the implementation of the technical fix act to favor the continuation of the governance regime in the face of system degradation (HM, JA);

- Lock-in: To respond to the symptomatic expressions of social and ecological degradation in the target system, additional technical fixes or the original technical fix are implemented. These then serve to "deepen the pathology" (Holling and Meffe 1996:331). This process, rather than affecting underlying drivers of the new problems, treats proximate symptoms, uncoupling the fundamental drivers from the experiences of important decision makers, and allowing the governance of the system to avoid fundamental changes (HM, JS).

\section{FURTHER UNPACKING THE PATHS}

\section{Enabling path}

The enabling path $[1,2,3,4,5]$ is constituted by two elements describing the target system and three elements of the governance of this system. For Holling and Meffe (1996) this is a natural system, while Scott (1998) explicitly entertains both natural and social systems as subjects of command-and-control style governance. The primary attributes of the target system, and the supposed problem associated with it, have been the subject of a large amount of literature, including Rittel and Webber's (1973) discussion of "wicked problems," and the concept of chaotic dynamics, both of which have been applied to characterize natural resource systems that humans govern (Acheson and Wilson 1996, Jentoft and Chuenpagde 2009).

Similarly, a large amount of literature associated with the study of resilience and vulnerabilities of social-ecological systems has emphasized their nonlinear self-reinforcing dynamics, tendency to stabilize in particular states, and the high levels of irreversibility in moving from state to state (Scheffer et al. 2001, Gunderson and Holling 2002). The commonality among these characterizations is that they emphasize how difficult it is to understand and control complex, real-world systems and problems because of the irreversibilities and potentially irreducible uncertainties associated with their own dynamics as well as the very interventions designed to manage them.

The second primary feature of the target system is the historical disempowerment of the human actors it contains. In the context of commons management settings, such actors are generally natural resource users. This creates a power imbalance between the centralized authority and the human subjects it aims to govern, facilitating the implementation of the technical fix. Additionally, Scott (1998) and Acheson (2006) emphasize that the technical fix itself can exacerbate this disempowerment of local resource users. This can result from lost autonomy, due in part to the integration of resource users into highly capitalist and productivist economies, or the "concentration of the resource in the hands of local elites or corporations" (Acheson 2006:126).
Scott (1998) emphasizes the irony of this outcome given that the rhetoric of high modernism predicts that social progress will be wrought from technical interventions.

Turning to features of governance, most prominent is the presence of a centralized state with authority over a large social-ecological system paired with a high level of disempowerment of the subjects of this state's governance initiatives. States can, in fact, fail in ways other than those documented here, and Acheson (2006) devotes some attention to this; because these are somewhat distinct arguments, they are not included here. Moreover, as Scott (1998) emphasizes and I emphasize here, the centralized authority need not be a public entity: the fact that it is hierarchically centralized is the key feature of the argument.

Next, and equally important, is the presence of a set of technical professionals who lay claim to generalizable technical knowledge via the analytical simplifications that provide leverage to exert control over the target system. When endowed with the ideology of high modernism and substantial authority over the target system, such actors can enforce these simplifications with the predicted results.

Together, these preconditions set the stage for the implementation of a technical fix. Each technical fix has two primary and mutually interdependent characteristics: analytical simplification and panacea thinking $[6,13]$, which set the stage for the second and third paths in the pathology. Each of these paths can be seen to start with the process of analytical simplification because the implementation of a technical fix to multiple contexts depends on the prior analytical simplification of such contexts [12].

\section{Panacea path}

Holling and Meffe (1996) write little about this path, whereas Scott (1998) and Acheson (2006) describe ways in which panaceas can fit poorly with aspects of target systems. The problem of a lack of social-ecological fit resulting from the application of institutional and technological panaceas [14, 15] has received quite a bit of attention in the literature on community-based natural resource management and the governance of complex social-ecological systems (Ostrom 1990, 2007). The basic idea is that in applying a uniform set of rules and technologies to a diverse set of systems, there will inevitably be some systems with which these rules and technologies do not fit. This process becomes more likely when local resource users are not engaged during the decision-making process in ways that could incorporate local knowledge and institutions [16, 18]. One important distinction between this path and the next one (suppression) is that here, the technical fix introduces new features into the target system that do not mesh well with existing features, rather than introducing new features that replace previously existing features.

There are many examples in the literature of a lack of fit between an intervention and either ecological or social aspects of the target system. For ecological aspects, Scott (1998) and Acheson (2006) provide examples of schemes to cultivate and manage certain crops or livestock that are ill-suited to local natural environments. Lansing (1991) presents a now famous example wherein changes introduced by Green Revolution specialists in Balinese Subak irrigation systems interacted poorly with local pest control strategies and soil properties. For social aspects, Acheson (2006) mentions the introduction of irrigation infrastructure that 
interacted poorly with the traditions and institutional customs of local farmers, while Cox (2014) discusses problems that the New Mexico, USA state government faced when trying to impose its water management doctrine on local Hispanic farming communities.

\section{Suppression path}

An important part of the argument of TPCC is that as a governance system becomes more centralized and more dominated by technical experts, incentives to enable Scott's (1998) synoptic view increase $[3,4,6]$. Thus, one would expect increasing amounts of analytical oversimplification in more centralized, bureaucratic systems.

The majority of the analytical simplifications that are constructed usually have two distinctive characteristics. First, they focus on one productivist output that is desired from the target system, such as crop production from an agricultural field, timber production from a forest, or gross domestic product from an economy. Second, they offer analytical leverage in the control of the system to achieve this goal. The latter occur as analytical "just so stories," or plausible and intuitive-sounding narratives whose assumptions often go untested, and which lend themselves to fashionable institutional arrangements such as certain types of property rights (e.g., individual transferable quotas). Thus, analytical simplifications frequently offer up a primary goal for a system as well as the means by which this goal can be achieved in a tidy package. This simplification is then applied to the target system via control [7]. As Holling and Meffe (1996:329-330) state, "Such efforts attempt to replace natural ecological controls, which are largely unknown to us and highly complex and variable, with engineered constructs and manipulations that on the surface seem entirely within our control."

Unfortunately, while initially successful, this simplification process leads to several problems that the authors highlight. Both Holling and Meffe (1996) and Scott (1998) emphasize the effect that control has on reduced functional diversity of the target social or ecological system [8], while Acheson (2006) and Scott (1998) both emphasize that a lack of engagement with local users contributes to this suppression [16, 17]. This suppression then results in a loss of system resilience and thus systemic degradation $[9,10]$.

Scott (1998) makes an argument that depends less on the notions of resilience and disturbance than Holling and Meffe (1996). He describes a technical intervention as follows: "The formal scheme was parasitic on informal processes that, alone, it could not create or maintain. To the degree that the formal scheme made no allowance for these processes or actually suppressed them, it failed both its intended beneficiaries and ultimately its designers as well" (Scott 1998:6). He is arguing that the control exerted on the target system will suppress and replace critical social or ecological functions [8], and that without these functions, the target system will inevitably deteriorate [11].

Essentially, both Holling and Meffe (1996) and Scott (1998) argue that there are critically important elements left out of the analytical simplifications of technical managers, and that because these simplifications determine what can be measured and therefore controlled technocratically, the governance system will be blind to much of what matters in the target system. What is not managed will inevitably be sacrificed in favor of what is managed, and because the target system depends on these processes to sustain itself and adapt to disturbances, degradation will result.

It is important to note that there are well-established counterarguments to this particular element of TPCC. An alternative scenario could be that, following the establishment of a primary goal for a target system, other system components are in fact maintained by the fulfillment of this goal. This could result if these other components of the system, such as species habitat, are needed to support the goal and are therefore maintained by goal myopia. This is the theory behind much of the U.S. Endangered Species Act, which generally manages for a particular indicator species with the hope that supporting this species will ultimately support the larger habitat and target system. There is a long debate about the merits of single-species vs. ecosystembased management in environmental conservation that reflects these contradictory arguments (Simberloff 1998).

\section{Lock-in path}

The final path in TPCC, which I have labeled lock-in, is a process by which the governance system becomes locked into its practices of analytical simplification and control and responds to system degradation by treating proximate symptoms of the problem rather than the underlying drivers $[19,20,21]$. This process is a specific example of a more general phenomenon called "path dependence," which has been discussed extensively with respect to technological, economic, and institutional change (Arthur 1989, 1994, North 1990, Pierson 2000). As Pierson (2000:252) states:

This conception of path dependence, in which preceding steps in a particular direction induce further movement in the same direction, is well captured by the idea of increasing returns. In an increasing returns process, the probability of further steps along the same path increases with each move down that path. This is because the relative benefits of the current activity compared with other possible options increase over time. To put it a different way, the costs of exit-of switching to some previously plausible alternative - rise. Increasing returns processes can also be described as self-reinforcing or positive feedback processes.

Path dependence has also been used to emphasize the possible presence of multiple self-reinforcing equilibria in economic systems. Interestingly, Holling and Meffe (1996) devote much of the second half of their paper to this topic, with respect to ecological systems. There are parallel sets of literature on the presence of self-reinforcing processes and multiple equilibria in economic and ecological systems (e.g., Myerson 1999, Scheffer et al. 2001).

Of the three works synthesized here, Holling and Meffe (1996:331) have the most to say about the process of lock-in within TPCC: "If the response to this pathology by other interests, such as the environmental community, is exclusively demand for tighter regulation and prohibition, then the pathology is deepened, because this applies a command-and-control solution to a problem initiated by command and control." They also describe several factors that cause this behavior: "At the same time, 
economic activities exploiting the resource benefit from success and expand in the short term, and we witness greater capital investment in activities such as agricultural production, pulp mills, suburban development, and fishing and hunting," which leads to "...an increasing dependency on continued success in controlling nature," and "...with dependency comes denial, demands by economic interests to keep and expand subsidies, and pressure for further command and control." (Holling and Meffe 1996:331).

Much of what drives the lock-in behavior is the original process of capitalization and control [19, 20]. Scott (1998) does not explicitly mention this dynamic, but there are examples of it in his case studies. For example, in describing the development of "scientific forestry," Scott (1998:21) describes the following dynamic:

\begin{abstract}
As pioneers in scientific forestry, the Germans also became pioneers in recognizing and attempting to remedy many of its undesirable consequences. To this end, they invented the science of what they called 'forest hygiene.' In place of hollow trees that had been home to woodpeckers, owls, and other tree-nesting birds, the foresters provided specially designed boxes. Ant colonies were artificially raised and implanted in the forest, their nests tended by local schoolchildren. Several species of spiders, which had disappeared from the monocropped forest, were reintroduced. What is striking about these endeavors is that they are attempts to work around an impoverished habitat still planted with a single species of conifers for production purposes. In this case, "restoration forestry" attempted with mixed results to create a virtual ecology, while denying its chief sustaining condition: diversity.
\end{abstract}

\section{CONCLUSION}

\section{Benefits of formalization}

There are several ways in which future research can benefit from the formalization process just discussed. An important point to make before discussing these is that scholars need not share in this precise understanding of the theory to benefit from this exercise. While this could be seen as an exercise in standardization, the formalization presented here can hopefully support more rigorous discussions of the different ways in which scholars view this important theory.

First, the formalization serves as an accessible reference for scholars to understand the explicit details of TPCC as characterized by several seminal works. This understanding can help scholars both to test the empirical predictions that are supported by the theory and to evaluate the extent to which a case under examination fits such predictions and thus meaningfully belongs to a larger population of similar cases that are amenable to the same theoretical characterizations and analytical approaches. Second, this exercise also helps scholars understand the nuances that distinguish how each of these works tends to view the dynamics involved, with Holling and Meffe (1996) and Acheson (2006) focusing exclusively on natural resource management, and Scott (1998) also examining the governance of social systems. Additionally, whereas Holling and Meffe (1996) focus exclusively on the suppression path, the other authors also emphasize the importance of the panacea path; I have shown how each path ultimately depends on the analytical simplification inherent in technical fixes. Finally, Holling and Meffe (1996) and Scott (1998) both provide details with respect to the lock-in path, which Acheson (2006) does not emphasize. It is thus through the overlapping descriptions of each work that the full details of the theory can be understood.

\section{Alternatives to command and control}

An interesting question is: If TPCC is commonly accepted and there are predictable problems with centralized, top-down governance, are there alternatives that would suffer less from these problems without incurring their own? Presumably something with a less top-down focus would be desirable. There are, however, several problems with the assumption that some type of inverse theory to TPCC is logically implied by TPCC. Such a theory might stipulate that private (as opposed to public), decentralized governance arrangements with more goal diversity and less control and simplification would perform well. However, there are several problems with this inverse theory. First, if this argument is taken to its limit, there would be a total lack of social control over social and ecological systems whereby individual actors are free to do what they will. One problem with this approach is that it leads to the tragedy of the commons (Hardin 1968). Indeed, as Holling and Meffe (1996:329) describe, the ways in which modern society exerts control over social and ecological systems "is undeniably to our individual and collective benefit." Indeed, some measure of control is implied by any type of governance, such that the question posed to policy analysts is not whether control is needed, but rather, how much and what types of control.

Similarly, some degree of analytical simplification is likewise necessary, as Scott (1998:11) states when describing technical knowledge: "Certain forms of knowledge and control require a narrowing of vision. The great advantage of such tunnel vision is that it brings into sharp focus certain limited aspects of an otherwise far more complex and unwieldy reality." Scott (1998) emphasizes that, through the process of "administrative ordering," the target system is made more legible to centralized managers and technical experts by providing them a synoptic view of the system. And regardless of what type of knowledge is being discussed, any understanding of a target social or ecological system will be necessarily incomplete. If any governmental organization tried to measure everything about a target system that it wanted to affect, it would likely exhaust its resources long before it was able to accomplish this. This is the argument behind the indicator species approach.

Additionally, decentralizing will not necessarily alleviate the problems associated with path dependence and lock-in. As demonstrated by Cody et al. (2015) and Cox et al. (2016b), communities of natural resource users, while holding important advantages such as a wealth of local ecological knowledge (Berkes 2012), are perfectly capable of avoiding fundamental solutions by choosing technical, symptomatic solutions to their problems. The factors that encourage lock-in overlap to some extent with the factors that can make it difficult for communities to act collectively to sustain a shared resource.

Shifting from public to private management does not necessarily help either. The status of being public or private does not entirely 
determine the status of being centralized or decentralized: many modern, private, particularly corporate, actors that manage and use natural resources are extremely hierarchical and exhibit many of the same behaviors of analytical simplification and control through capitalization. As Scott (1998:87) states, "A private corporation aiming to maximize sustainable timber yields, profit, or production will map its world according to this logic and will use what power it has to ensure that the logic of its map prevails. The state has no monopoly on utilitarian simplifications." Moreover, as Fitzgerald (2003) discusses, the public sector's infatuation with legibility and control via technical fixes is mirrored by similar developments in the private sector, as perhaps most famously represented by the rise of Frederick Taylor's scientific management of factories, or "Taylorism," which has spread to natural resource management sectors as well.

Additionally, the private sector suffers no less from the processes of path dependence and lock-in, as the literature on path dependence makes rather clear (Arthur 1994). In the modern agricultural sector, for example, a combination of public and private actors and activities now serve to lock much of that sector into many of the behaviors observed in TPCC (Cowan and Gunby 1996). Finally, and paradoxically, such privatized management is often advocated by fairly centralized governmental agencies. Indeed, many of the analytically simplistic "just so stories" mentioned earlier advocate for highly decentralized arrangements. Private property rights and associated policy instruments such as individual transferable quotas, for example, are frequently argued by technical professionals to have distinct benefits in achieving positive social and ecological outcomes (Costello et al. 2008). The meaningfulness of the public vs. private distinction is not obvious or clear in such cases.

\section{What should adapt to what?}

An additional question that TPCC poses is: Under what conditions should an attempt be made to address more proximate symptoms vs. more underlying drivers of a problem? The answer to this depends in part on what is a symptom vs. an underlying driver. Pollution, for example, could be considered to be a symptom of an underlying problem rather than a problem itself, in which case, the amelioration of this pollution is a symptomatic solution rather than a fundamental one. This is the perspective that some scholars from the field of industrial ecology take when they describe pollution remediation as essentially being "less bad" (Braungart et al. 2007). Ameliorating the symptoms of industrially emissive activities enables the continuance of these same activities, possibly to long-term detriment. Similarly, Meadows (1999), in her famous work on leverage points, relegates policy-related interventions to the last place on her list:

\section{But changing these variables rarely changes the behavior of the national economy system. Whatever cap we put on campaign contributions, it doesn't clean up politics. The Fed's fiddling with the interest rate hasn't made business cycles go away. After decades of the strictest air pollution standards in the world, Los Angeles' air is less dirty, but it isn't clean. Spending more on police doesn't make crime go away.}

However, Meadows (1999) does allow for the possibility that such symptomatic solutions can trigger more substantial structural change. This may be the most realistic or effective way forward, depending on just how strongly locked in a system is.

\section{Concluding remarks}

I think that TPCC is a powerful theory, not only because of its importance in the field of environmental governance and governance more broadly. The issues of simplification, goal myopia, and control are ubiquitous in decision-making settings. This includes, for example, the following settings and questions:

- Hiring and admission decisions: What is to be measured and therefore "valued" in the applicants?

- Personal goals: When are we willing to bear the sacrifices necessary to achieving a particular goal, and when does the setting of the goal itself need to adapt to our available resources and competing goals?

- Professional reward systems: Should the most quantitatively measurable outputs such as publications and grant funds be prioritized over more diffusely productive activities?

- Parenting decisions: How much control over a child is too much?

TPCC is also likely applicable to other sectors. In his critique of modern psychiatry, Carlat (2010) makes arguments very similar to those described here regarding the role of experts and technical knowledge. Most generally, this discussion of TPCC reinforces the general importance of striking a balance between two extremes along multiple dimensions by showing how things can go wrong when one set of such extremes is chosen. I thus note the complementarity of Holling and Meffe's (1996) "golden rule" of environmental management (i.e., maintain critical types and amounts of ecological variation) with the pursuit of Aristotle's "golden mean," or the desirable middle ground between two extremes along each of the dimensions described by TPCC.

Responses to this article can be read online at: http://www.ecologyandsociety.org/issues/responses. php/8698

\section{LITERATURE CITED}

Acheson, J. M. 2006. Institutional failure in resource management. Annual Review of Anthropology 35:117-134. http:// dx.doi.org/10.1146/annurev.anthro.35.081705.123238

Acheson, J. M., and J. A. Wilson. 1996. Order out of chaos: the case for parametric fisheries management. American Anthropologist 98(3):579-594. http://dx.doi.org/10.1525/ aa.1996.98.3.02a00110

Arthur, W. B. 1989. Competing technologies, increasing returns, and lock-in by historical events. Economic Journal 99 (394):116-131. http://dx.doi.org/10.2307/2234208

Arthur, W. B. 1994. Increasing returns and path dependence in the economy. University of Michigan Press, Ann Arbor, Michigan, USA. http://dx.doi.org/10.3998/mpub.10029

Berkes, F. 2012. Sacred ecology. Third edition. Routledge, New York, New York, USA.

Braungart, M., W. McDonough, and A. Bollinger. 2007. Cradleto-cradle design: creating healthy emissions - a strategy for ecoeffective product and system design. Journal of Cleaner 
Production 15(13-14):1337-1348. $\quad$ http://dx.doi.org/10.1016/j. jclepro.2006.08.003

Carlat, D. J. 2010. Unhinged: the trouble with psychiatry-a doctor's revelations about a profession in crisis. Free Press, New York, New York, USA.

Cody, K. C., S. M. Smith, M. Cox, and K. Andersson. 2015. Emergence of collective action in a groundwater commons: irrigators in the San Luis Valley of Colorado. Society and Natural Resources 28(4):405-422. http://dx.doi.org/10.1080/08941920.2014.970736

Costello, C., S. D. Gaines, and J. Lynham. 2008. Can catch shares prevent fisheries collapse? Science 321:1678-1681. http://dx.doi. org/10.1126/science.1159478

Cowan, R., and P. Gunby. 1996. Sprayed to death: path dependence, lock-in and pest control strategies. Economic Journal 106(436):521-542. http://dx.doi.org/10.2307/2235561

Cox, M. 2014. Applying a social-ecological system framework to the study of the Taos Valley irrigation system. Human Ecology 42(2):311-324. http://dx.doi.org/10.1007/s10745-014-9651-y

Cox, M., S. Villamayor-Tomas, G. Epstein, L. Evans, N. C. Ban, F. Fleischman, M. Nenadovic, and G. Garcia-Lopez. $2016 a$. Synthesizing theories of natural resource management and governance. Global Environmental Change 39:45-56. http://dx.doi. org/10.1016/j.gloenvcha.2016.04.011

Cox, M., M. Wilson, and T. Pavlowich. 2016b. The challenges of local governance: gear-based fragmentation in the Dominican fishery of Buen Hombre. Marine Policy 63:109-117. http://dx.doi. org/10.1016/j.marpol.2015.09.029

Fitzgerald, D. 2003. Every farm a factory: the industrial ideal in American agriculture. Yale University Press, New Haven, Connecticut, USA. http://dx.doi.org/10.12987/yale/9780300088$\underline{137.001 .0001}$

Gunderson, L. H., and C. S. Holling, editors. 2002. Panarchy: understanding transformations in human and natural systems. Island Press, Washington, D.C., USA.

Hardin, G. 1968. The tragedy of the commons. Science 162 (3859):1243-1248. http://dx.doi.org/10.1126/science.162.3859.1243

Holling, C. S., and G. K. Meffe. 1996. Command and control and the pathology of natural resource management. Conservation Biology 10(2):328-337. http://dx.doi.org/10.1046/

j.1523-1739.1996.10020328.x

Jentoft, S., and R. Chuenpagdee. 2009. Fisheries and coastal governance as a wicked problem. Marine Policy 33(4):553-560. http://dx.doi.org/10.1016/j.marpol.2008.12.002

Lansing, J. S. 1991. Priests and programmers: technologies of power in the engineered landscape of Bali. Princeton University Press, Princeton, New Jersey, USA.

Meadows, D. 2009. Leverage points: places to intervene in a system. Solutions 1(1):41-49. [online] URL: http://www. thesolutionsjournal.org/node/419

Myerson, R. B. 1999. Nash equilibrium and the history of economic theory. Journal of Economic Literature 37 (3):1067-1082. http://dx.doi.org/10.1257/jel.37.3.1067
North, D. C. 1990. Institutions, institutional change and economic performance. Cambridge University Press, Cambridge, UK. http://dx.doi.org/10.1017/cbo9780511808678

Ostrom, E. 1990. Governing the commons: the evolution of institutions for collective action. Cambridge University Press, Cambridge, UK.

Ostrom, E. 2007. A diagnostic approach for going beyond panaceas. Proceedings of the National Academy of Sciences 104 (39):15181-15187. http://dx.doi.org/10.1073/pnas.0702288104

Ostrom, E., J. Burger, C. B. Field, R. B. Norgaard, and D. Policansky. 1999. Revisiting the commons: local lessons, global challenges. Science 284(5412):278-282. http://dx.doi.org/10.1126/ science.284.5412.278

Pierson, P. 2000. Increasing returns, path dependence, and the study of politics. American Political Science Review 94 (2):251-267. http://dx.doi.org/10.2307/2586011

Rittel, H. W. J., and M. M. Webber. 1973. Dilemmas in a general theory of planning. Policy Sciences 4(2):155-169. http://dx.doi. org/10.1007/bf01405730

Scheffer, M., S. Carpenter, J. A. Foley, C. Folke, and B. Walker. 2001. Catastrophic shifts in ecosystems. Nature 413:591-596. http://dx.doi.org/10.1038/35098000

Schlager, E. 2007. A comparison of frameworks, theories, and models of policy processes. Pages 293-319 in P. A. Sabatier, editor. Theories of the policy process. Westview Press, Boulder, Colorado, USA.

Scott, J. C. 1998. Seeing like a state: how certain schemes to improve the human condition have failed. Yale University Press, New Haven, Connecticut, USA.

Simberloff, D. 1998. Flagships, umbrellas, and keystones: is single-species management passé in the landscape era? Biological Conservation 83(3):247-257. http://dx.doi.org/10.1016/S0006-3207 (97)00081-5

Stavins, R. N. 2003. Experience with market-based environmental policy instruments. Pages 355-435 in K.-G. Mäler and J. R. Vincent, editors. Handbook of environmental economics: environmental degradation and institutional responses. Volume 1. Elsevier, Amsterdam, The Netherlands. http://dx.doi.org/10.1016/ S1574-0099(03)01014-3 